Artigos

\title{
0 lugar da comunidade na teoria do reconhecimento de Axel Honneth
}

Arim Soares do Bem

Resumo: O objetivo deste artigo é demonstrar, por meio de uma reconstrução teórico-normativa e histórica, o lugar e o relevo da comunidade na Teoria do Reconhecimento de Axel Honneth e explicitar as suas formas de aparição nos campos disciplinares (filosofia, psicologia social, psicanálise e teoria sociológica) e nas esferas de interação (amor, direito e estima social) por ele privilegiados.

Palavras-chave: Teoria do Reconhecimento e comunidades; Comunidades e esferas de interação; Mudança estrutural das comunidades e reconhecimento.

The status of the community in Axel Honneth's recognition theory

Abstract: The aim of this paper is to demonstrate, from a theoretical-normative and historical reconstruction, the place and the community's prominence in Axel Honneth's Theory of Recognition and to explain its forms of appearance in the disciplinary fields (philosophy, social psychology, psychoanalysis and sociological theory) and in the spheres of interaction (love, right and social esteem) which he privileged.

Keywords: Theory of Recognition and communities; Communities and interaction spheres; Structural change of communities and recognition.

1 Instituto de Ciências Sociais da Universidade Federal de Alagoas (ICS - UFAL) - Maceió - Brasil - mebsores@gmail.com 


\section{Introduç̃̃̃o}

A obra de Axel Honneth, considerado um dos mais importantes membros da terceira geração da Escola de Frankfurt, representa considerável esforço pela fundamentação e sistematização teórica da relação entre intersubjetividade e constituição da identidade e experiência individual e social em sociedades modernas e contemporâneas. Toda tentativa de acessar o pensamento do autor, em permanente e simultâneo processo de expansão e revisão, pode evidenciar-se como tarefa tragicamente fadada ao fracasso ou à deformação, se não forem considerados os seus minuciosos e sutis esforços pela articulação de diferentes campos disciplinares, como a filosofia, a teoria sociológica, a psicanálise e a psicologia social, e também de diferentes esferas de interação, tanto em seus aspectos históricos, como lógicos e estruturantes. $\mathrm{O}$ objetivo geral deste artigo é reconstruir o percurso feito pelo próprio autor no sentido de realocar, nos campos e esferas anteriormente referidos, as bases para a elaboração de parâmetros normativos aptos a sustentar a sua noção de sujeito, ancorada na concepção formal de eticidade e reconhecimento intersubjetivo. Em termos específicos, o objetivo deste artigo é demonstrar o lugar ocupado pela "comunidade", em suas várias formas de manifestação, na gênese e nos desdobramentos teóricos e históricos de suas reflexões.

A dimensão mais geral e abrangente da Teoria do Reconhecimento de Axel Honneth e que constitui e perpassa todos os seus campos disciplinares e esferas de interação, é a intersubjetividade. A intersubjetividade é a argamassa que fundamenta a tensa e contraditória relação entre subjetividade e sociedade e permite a explicitação da formação da identidade individual e social, mediando a formação e constituição da liberdade, da autoconsciência e das orientações para a ação individual e coletiva, que são instâncias fundamentais no processo de sedimentação das diferentes formas de socialização e de determinação da vida social. Todos os campos disciplinares e esferas de interação são constituídos por perspectivas epistêmicas, fenomênicas e históricas. A dimensão epistêmica pressupõe a investigação sistemática da realidade e está aberta, na obra de Honneth, tanto em relação ao seu objeto, como aos seus condicionantes históricos. A dimensão fenomênica explicita as expectativas normativas derivadas da experiência subjetiva de indivíduos e grupos sociais em relação às suas condições de existência e a dimensão histórica atravessa todas as relações nos campos e esferas considerados, mesmo que em alguns textos ou obras tenham mais ou menos relevo. 


\section{A gênese do reconhecimento nos escritos do jovem Hegel}

No Hegel de Iena, que tanto influenciou Honneth em sua obra fundante, Luta por Reconhecimento (2003), o modelo de uma luta social entre os homens nas obras de Maquiavel e Hobbes é retomado, e a história da constituição teórica nesses autores é reconstruída tanto em relação aos seus aspectos diferenciais como de convergência. Em Maquiavel manifesta-se a ideia de que os indivíduos se contrapõem numa concorrência desenfreada de interesses, enquanto em Hobbes funda-se a ideia do contrato social ancorado na soberania do Estado. Em ambos, a dinâmica social é balizada por meio da noção de luta por autoconservação e esta representação tornou-se possível com a perda de vigor, na idade média, da doutrina política da antiguidade, que concebia o homem como um ser capaz de estabelecer comunidades éticas ancoradas na arena política da Polis (Honneth, 2003: 31).

Embora retome, no ensaio Maneiras Científicas de tratar o Direito natural, de 1802, as premissas do modelo conceitual de Maquiavel e Hobbes, Hegel procurou superar os entraves atomísticos do Direito natural moderno, pois para ele este só consegue pensar a comunidade dos homens segundo a ideia da associação de sujeitos individuais isolados e não segundo a ideia de uma unidade ética (Idem: 39-40). O objetivo de Hegel é, neste profícuo período de sua produção em Iena, desenvolver um novo sistema categorial que permita fundar uma teoria que parta da noção de vínculos éticos entre os sujeitos. Como Honneth salienta (Idem: 43):

Diferentemente do que se passa nas doutrinas sociais atomísticas, deve ser aceito como espécie de base natural da socialização humana um estado que desde o início se caracteriza pela existência de formas elementares de convívio intersubjetivo.

O que Hegel propõe para superar o atomismo do Direito natural moderno e explicar a passagem do estado de eticidade natural para a formação de uma organização solidária e intersubjetiva da comunidade de homens não é, pois, regular o convívio social por meio da superação da natureza supostamente egocêntrica do homem (implícita no Direito natural), mas pressupor, desde o início, a existência de relações intersubjetivas como condição imanente da socialização humana. Hegel extrai, para tanto, da ontologia aristotélica o fundamento teleológico que lhe possibilita desdobrar a substância ética original, mediante um processo conflituoso e negocial, até alcançar a unidade universal da totalidade ética (Idem: 44). É o fundamento teleológico que permite a Hegel 
situar a eticidade como um vir-a-ser que possibilita superar as limitações das particularidades unilaterais e universalizar os potenciais morais já inscritos na eticidade natural, desvelando o que nessa forma originária de eticidade ainda se apresenta como algo "não desdobrado" (Idem, Ibidem). Mas foi somente após reinterpretar a doutrina do reconhecimento de Fichte que Hegel conseguiu caracterizar o vir-a-ser da eticidade de modo a considerar a sociedade como uma estrutura organicamente enraizada na ideia de reconhecimento intersubjetivo.

Com efeito, entre os anos 1794 e 1800, Fichte desenvolveu a sua concepção idealista da história da autoconsciência, considerando uma rede de reciprocidade na gênese da personalidade e da intersubjetividade, sendo tomado por Düsing (1986) como o primeiro teórico da interpessoalidade. No entanto, em Fichte, o Eu permanece como objeto e sujeito da constituição de si mesmo e é fortemente ancorado em bases transcendentais. É nos Fundamentos do Direito Natural (Grundlage des Naturrechts), de 1796, que se apresenta a ideia do reconhecimento como resultado de uma ação recíproca entre os indivíduos, que adquire validade objetiva no âmbito das relações jurídicas. Pressuposto da reciprocidade é a ação livre dos indivíduos e a limitação igualmente recíproca da própria esfera de ação em favor do outro, de modo a assegurar a ideia de uma comunidade em que os sujeitos livres não se contraponham entre si, mas engendram relações éticas fundadas numa intersubjetividade prática ancorada no reconhecimento (Honneth, 2003: 46-47).

Foi somente após a apropriação, revisão e ampliação do modelo teórico do reconhecimento de Fichte que Hegel conseguiu o avanço fundamental no sentido de determinar o potencial interno da eticidade humana, de forma a reinterpretar e deslocar a noção de uma luta de todos contra todos implícita no Direito natural para uma concepção mais exigente de individualidade (Idem: 47), introduzindo uma perspectiva de luta social inovadora que faz configurar os conflitos práticos entre os indivíduos como momentos significativos de um movimento ético. A reinterpretação de pressupostos hobbesianos e fichteanos já permite a Hegel, no Sistema de Eticidade (System der Sittlichkeit), de 1802, substituir a luta de todos contra todos pela inscrição das formas elementares de reconhecimento no bojo do que ele desenvolve, nesta obra, sob o título de eticidade natural, à qual opõe, no outro extremo, a eticidade absoluta.

Nos escritos teológicos, que abarcam a produção de Hegel durante a última década do Século XVIII, fazia-se presente a ideia do crime como ato destrutivo praticado pelos que estão incluídos no convívio social apenas negativamente. $\mathrm{O}$ crime seria a expressão de um reconhecimento incompleto, diante do qual o criminoso reagiria contra as abstrações e unilateralidades estruturais das relações 
jurídicas formais. Fato é que nos escritos teológicos já estava em gestação tanto o embrião de uma futura teoria da intersubjetividade como uma das esferas de interação que ganha contornos mais precisos - mas ainda assim não completamente desenvolvidos - no Sistema de Eticidade - o amor. Principalmente no Esboço sobre Religião e Amor, de 1797-1798, ainda sob a influência do amigo (e) poeta Hölderlin e também dos desdobramentos práticos da Revolução Francesa, o engajamento terreno deveria, para Hegel, substituir o coagulado discurso religioso sobre o céu e transformar o que no cristianismo se corporificava em torno da Lei, traduzida no mandamento Não Matarás, em base substantiva para o amor ao próximo, capaz de levar os homens separados uns dos outros a se intercomunicarem e se reconhecerem uns nos outros (Konder, 1991: 10).

Se é fato que o crime reaparece no Sistema de Eticidade e - a propósito da apropriação da posse pelo roubo - fere a forma universal do reconhecimento jurídico, abre, por outro lado, simultaneamente, o processo de uma luta cujo resultado eleva pretensões de identidades que configuram aprendizados prático-morais aptos a integrarem sujeitos individuais em comunidades permeadas pela lógica da solidariedade (Honneth, 2003:58). Com efeito, é a pessoa lesada que se coloca inteira em defesa da honra violada, arriscando mesmo a própria vida para reconstruir a sua integridade. Apesar disso, o papel do crime como formador necessário - ainda que de modo indireto, intermediário e negativo da eticidade, assim como os motivos de sua instrumentalização, permanecem lacunares e ambivalentes no Sistema de Eticidade e depõem, segundo Honneth, contra Hegel nesta fase de sua produção. Honneth credita tais problemas e dificuldades, em parte, à ausência, ainda, de conceitos complementares de uma teoria da intersubjetividade mais abrangente nesta fase da obra de Hegel.

Na Filosofia do Espírito, de 1803-1804, opera-se uma transformação significativa no pensamento de Hegel. Desse ponto em diante, a natureza perde seu significado ontológico originário e passa a demarcar o domínio da realidade oposto ao espírito. A teleologia aristotélica cede lugar ao processo de formação do espírito, deslocando-se os motivos do conflito inscrito na interação para o interior do conflito humano. Neste novo contexto (Honneth, 2003: 64):

O indivíduo só pode se proporcionar um sentimento de garantia a respeito de ser reconhecido por seu parceiro de interação mediante a experiência da reação prática com que aquele responde a um desafio deliberado, ou mesmo a uma provocação.

Enquanto no Sistema de Eticidade o relevo era colocado por Hegel no quadro referencial que abarcava as relações comunicativas de teor normativo 
constituintes das formas de interação social, a Filosofia do Espírito passa a privilegiar as diferentes etapas de automediação da consciência, estabelecendo-se uma confrontação teórica e prática dos indivíduos com o seu entorno, derivando-se daí diferentes operações de reflexão entre o espírito e o mundo (Idem: 65) e eliminando-se, por decorrência, a ideia de uma intersubjetividade prévia da vida humana. Honneth salienta a este respeito que, se ocorreram, com a guinada do pensamento de Hegel, avanços categoriais que permitiram estabelecer uma diferenciação entre vários conceitos de pessoas, o preço que ele teve que pagar foi a renúncia a um intersubjetivismo forte, já que a nova abordagem abandona as alternativas da teoria da comunicação (Idem: 66).

A Realphilosophie, de 1805-1806, é o último texto de Hegel anterior à Fenomenologia do Espírito (publicado no ano seguinte) e já deixa entrever a operacionalidade do avanço paradigmático realizado, sendo considerada por Honneth uma síntese consequente das mudanças teóricas situadas entre o Sistema de Eticidade e a Filosofia do Espírito (Idem: 67). 0 movimento do espírito não pode mais se limitar somente à explicação das relações éticas, pois este obtém agora "uma visão de sua própria constituição interna com base na 'arte, religião e ciência" (Idem: 70). Ao perder a centralidade que lhe era anteriormente imputada, a teoria da eticidade não é mais o vetor para a constituição da consciência humana, pois esta:

deixa de ser integrada no processo de construção de relações sociais éticas como uma dimensão constitutiva, e, inversamente, as formas de relacionamento social e político dos homens passam a ser somente etapas de transição no processo de formação da consciência humana que produz os três media de autoconhecimento do espírito (Idem: 71).

Com a virada programática altera-se também a estrutura categorial de Hegel. O que no Sistema de Eticidade se apresentava como eticidade natural transforma-se agora em espírito subjetivo, mediado pelo espírito efetivo, até alcançar a sua forma absoluta. Honneth sugere que, por ter situado o modelo estrutural da luta por reconhecimento enquanto parte constitutiva do primeiro capítulo, que trata do espírito subjetivo, Hegel tê-lo-ia considerado a força motriz que permite acesso ao espírito absoluto (Idem: 72). Mas, antes de alcançar a etapa final, o espírito subjetivo precisa experienciar o mundo e levar os sujeitos a se situarem enquanto portadores de direitos e partícipes da vida institucionalmente regulada, que se concretiza no espírito efetivo - quando os indivíduos se concebem como sujeitos de produções práticas (Idem: 73) e se estabelece um nexo 
significativo entre o trabalho, o instrumento e o produto daí derivado (Idem: 74). Aqui se evidencia que a realidade não é mais apenas categoricamente constituída, mas sim por meio do trabalho, que exige disciplina e autocoerção. Ao engendrar a posse, o trabalho possibilita o reconhecimento no domínio da troca e, neste sentido, permite pensar o contrato, agora, como reciprocidade das orientações de ações entre os defrontantes (Idem: 98).

Se o contrato impõe a adoção de um compromisso reciprocamente assumido, a sua quebra legitima a coerção e dá início a um processo conflituoso que instaura a luta por reconhecimento na esfera de interação do direito, pois a lesão jurídica é vista como uma forma de desrespeito (Idem: 99). De agora em diante, diferentemente do que se dá no Sistema de Eticidade, em que o crime é lacunar e problematicamente situado como mediador entre a eticidade natural e a absoluta, Hegel o inscreve no interior das regras típicas das relações de reconhecimento (Idem: 100) e este adquire a função de restaurar institucionalmente o direito, dando-se, assim, a passagem do direito natural ao direito positivo (Idem: 103).

No domínio do espírito efetivo, porém, quando este se exterioriza e se projeta na objetividade do mundo, liberando-se do arbítrio subjetivo, a eticidade é desenvolvida como emanando da esfera estatal. Honneth afirma a existência de um conflito entre modelos de eticidade, já que Hegel teria empregado, no âmbito de sua reflexão sobre o Estado, figuras de pensamento próprias da filosofia da consciência (Idem: 109). Este procedimento o teria levado a reprimir a teoria do reconhecimento e a formalizar o Estado somente enquanto autoridade monologicamente constituída, chegando mesmo a demonstrar respeito por Maquiavel, que havia sido enfaticamente por ele criticado (Idem: 110).

Ao final da exposição sobre o Hegel de Iena no primeiro capítulo da obra Luta por Reconhecimento (2003), Honneth faz, na segunda parte da obra, uma atualização sistemática sobre a estrutura das relações de reconhecimento, em que formaliza algumas críticas e objeções ao filósofo idealista, destacando-se, segundo os objetivos deste artigo, duas, a saber: a primeira, como já salientamos, está relacionada ao fato de Hegel (supostamente) reprimir a teoria do reconhecimento no contexto de obras futuras, em que o Estado apresentar-se-ia como fonte autárquica de autoridade e ter-se-ia forjado a ideia de um sujeito - o citoyen - submisso e obediente àquele (Idem: 112); e a quinta objeção, que considera como os maiores obstáculos em Hegel as suas premissas metafísicas (Idem: 117). É a consideração à quinta crítica que leva Honneth a dar um salto gigantesco, após a exposição sobre o Hegel de Iena nos três capítulos que compõem a parte I de sua obra, para outro campo disciplinar - a psicologia social 
-, na segunda parte, em que aborda sobre a relação entre o reconhecimento e a socialização em George H. Mead, que teria oferecido um quadro referencial teórico capaz de levar à transformação naturalista, pós-metafísica, da ideia hegeliana (Idem: 122).

O que queremos ressaltar aqui é que o salto gigantesco das obras do período de Iena para um campo disciplinar exterior à produção filosófica de Hegel está também relacionado à consideração crítica de Honneth, segundo a qual dar-se-ia um (suposto) expurgo da eticidade e da intersubjetividade nas obras de maturidade do pensador idealista. Todavia, a finalização abrupta da exposição sobre a teoria do reconhecimento de Hegel apenas no domínio de suas obras de juventude está também relacionada aos limites do campo de visão do próprio Honneth, que, por ocasião da publicação de Luta por Reconhecimento, em 1992, estava convencido de que nas obras da maturidade de Hegel não se encontrariam elementos férteis e produtivos de uma teoria do reconhecimento. Por esta razão, bem mais tarde, notadamente em obra publicada em 2010, intitulada Das Ich im Wir. Studien zur Anerkennungstheorie (O Eu no Nós. Estudos sobre a Teoria do Reconhecimento), Honneth corrige seus pressupostos e dá maior precisão às posições desenvolvidas na obra de 1992. No prefácio da obra de 2010, na qual revisa a interpretação pretérita de Hegel, Honneth é direto e preciso no exercício da autocrítica:

Enquanto eu, na obra Luta por Reconhecimento, partia da premissa de que só os Esboços de Sistema de Iena continham elementos férteis de uma teoria do reconhecimento, deixei-me mais tarde, por decorrência de uma ocupação mais aprofundada com os escritos de maturidade, instruir por melhor compreensão; atualmente não creio mais que Hegel tenha sacrificado seu intersubjetivismo inicial na direção de um desenvolvimento monológico de sua concepção do espírito (Honneth, 2010: 7-8, tradução nossa).

No mesmo prefácio à publicação de 2010, Honneth evidencia a base por meio da qual fora levado à revisão do que considerou ser, na obra de 1992, uma "ainda vaga reflexão" sobre os fundamentos da intersubjetividade nas obras maduras de Hegel (Honneth, 2010: 7). Neste sentido, atribui ao confronto realizado com Nancy Fraser e às atividades desenvolvidas no âmbito das "Tanner-Lectures" da Universidade de Berkeley o impulso produtivo para a busca de maior precisão, aprofundamento e refinamento de sua obra. Do capítulo sobre a autoconsciência (Selbstbewusstsein) na obra Fenomenologia do Espírito de Hegel, Honneth extrai os elementos para demonstrar a permanência de um intersubjetivismo ainda forte nele, além daquele já identificado nas obras de juventude. 


\section{0 reconhecimento nas obras de maturidade de Hegel}

No primeiro capítulo da obra anterior referida (O Eu no nós), intitulado Do desejo ao reconhecimento. A fundamentação hegeliana da autoconsciência (Von der Begierde zur Anerkennung. Hegels Begründung von Selbstbewusstsein), Honneth considera que o objetivo de Hegel, na Fenomenologia do Espírito, era demonstrar que um sujeito somente pode alcançar a própria autoconsciência se entrar em uma relação de reconhecimento com outro sujeito (Idem: 16). Para expor a transição do ser natural para o espírito humano, Hegel parte do desejo (Begierde), etapa mais elementar de relação com o mundo objetivo, na qual o espírito aprende a interpretar a realidade com o objetivo de satisfazer as suas necessidades mais elementares (Idem: 19). A introdução da vida enquanto categoria presta-se à criação das condições para que o sujeito comece "a interpretar o mundo como dependente do próprio conhecimento e, com isso, a desenvolver a autoconsciência" (Idem, Ibidem, tradução nossa). Objeto do desejo imediato é a vida e não somente a atividade mental ou imaginária de um Eu sem corpo e não situado.

A vida leva, pois, a um Outro além e superior a ela, à consciência (Idem: 22). Mas mediada pelo desejo, a consciência da vida tende a fracassar em seu esforço por alcançar a autoconsciência, pois o sujeito, para satisfazer as suas necessidades, consome o objeto natural, todavia não pode impedir que este mantenha a sua autonomia, já que ele se reproduz, assim como o próprio desejo, sempre de modo renovado. O desejo mantém, pois, uma relação deficitária com a autoconsciência (Idem: 25) ao não permitir ao sujeito compreender-se como totalidade orgânica e como ser genérico (menschliche Gattung), em virtude de suas fantasias de onipotência diante da natureza (Idem: 26).

Para ascender à autoconsciência, o sujeito precisa de um quadro referencial mais amplo para ancorar a sua experiência - outro sujeito. Ambos devem, na interação, "limitar ou negar seus respectivos desejos egocêntricos, de modo que seu encontro se dê sem a intenção de mero consumo" (Idem, Ibidem, tradução nossa). Honneth sugere que Hegel teria tido, na Fenomenologia do Espírito, uma intenção mais ampla do que usualmente suposta: a de que os sujeitos "somente alcançam a autoconsciência com o suporte de uma experiência que já possui, em sentido elementar, um caráter moral" (Idem: 31, tradução nossa). A autolimitação é compreendida, assim, como o fundamento e o pressuposto de toda a moral. Limitando suas necessidades egocêntricas diante de um defrontante, o sujeito coloca a continuidade de suas ações em estreita dependência do comportamento daquele e, assim, a autolimitação 
pode ser vista por Hegel como a protomoral que fermenta as condições de formação da autoconsciência (Idem: 31).

Com relação à outra obra da maturidade de Hegel, os Princípios da Filosofia do Direito, suposta na obra Luta por Reconhecimento como não estando ancorada numa teoria do reconhecimento, Honneth a reavalia no segundo capítulo da antiga referida obra de 2010, intitulado $O$ império da liberdade realizada. A ideia hegeliana de uma Filosofia do Direito (Idem: 33, tradução nossa). O objetivo de Hegel na obra Princípios da Filosofia do Direito, teria sido, segundo Honneth, estabelecer os princípios fundamentais da ordem estatal liberal que significassem mais do que um mero aprofundamento sobre os fundamentos do moderno direito (Idem: 34), de modo a superar os déficits por ele identificados nos princípios jurídicos e permitir tratá-los sob o crivo do conceito de eticidade (Sittlichkeit) (Idem: 35). Para Hegel, uma formação estatal moderna constituída sob condições esclarecidas somente pode ser tomada como legítima e justificável se puder garantir a liberdade individual de cada um de seus membros (Idem: 35). O terreno do direito deve ser, pois, a vontade livre dos cidadãos, de forma que o sistema jurídico se institua enquanto o império da liberdade realizada (Idem: 35 ).

Honneth afirma que a intenção de Hegel não era apenas constituir o quadro referencial do direito, mas o império da autorrealização individual, furtando-se à mera formulação negativa dos princípios garantidos pelo Estado, como assente nas obras de Kant, Fichte e Rousseau (Idem: 36). Para tanto Hegel inicia sua reflexão opondo dois modelos de formação da vontade, considerando ambos incompletos e unilaterais. $\mathrm{O}$ primeiro é aquele segundo o qual a autodeterminação individual é interpretada como a capacidade de tomar decisões estrategicamente demarcadas pelo distanciamento de necessidades, desejos e pulsões. Neste modelo encontram-se embrionariamente componentes da liberdade individual, mas o resultado da decisão não levaria a nenhuma forma organizada de ação; muito pelo contrário: degradaria em perfeita incapacidade de ação (vollkommene Handlungslosigkeit) (Idem: 37). No segundo modelo, a liberdade individual é constituída segundo o padrão da decisão racional que antecipa finalidades para a ação e Hegel a compreende como uma forma de liberdade fundada meramente no arbítrio (Willkürfreiheit). $\mathrm{O}$ déficit desse modelo residiria no fato de a liberdade individual não penetrar o material da decisão e permanecer, pois, exterior ao seu conteúdo (Idem, Ibidem).

Segundo Honneth, Hegel teria buscado fundar um terceiro modelo de formação da vontade, sustentando-se na concepção dialética e promovendo a síntese das duas determinações unilaterais constitutivas dos dois modelos 
deficitários anteriormente citados, complementando-os, mas não apenas de modo formal. Para tanto, Hegel reinscreve a concepção de vontade dos escritos de juventude no novo contexto reflexivo. Naqueles textos, a vontade é considera livre quando "está em si, estando no outro" (bei sich selbst in einem Anderen). Esta forma de liberdade encontra nos escritos de juventude de Hegel exemplar tipificação no domínio do amor, que dá acesso ao conteúdo substancial da vontade de liberdade e a situa como atividade que possibilita superar a contradição entre subjetividade e objetividade:

Tão logo um sujeito, em virtude de sua vontade de decisão, se relaciona com algo no mundo que lhe permanece estranho por que nele ele não pode reconhecer uma ampliação ou uma parte de si mesmo, ele ainda não é realmente livre; ele somente alcança a completa liberdade quando neste outro ele permanece em si mesmo, quando experimenta suas propriedades ou particularidades como algo com o qual ele pode se identificar (Honneth, 2010: 38, tradução nossa).

É curioso observar que Honneth, ao se debruçar sobre a obra madura de Hegel descubra que no processo de reavaliação da mesma, ter-se-ia dado conta de que ali encontrar-se-iam ideias ainda mais marcantes em relação ao reconhecimento do que em seus escritos de juventude. Ele constata que deveria, em relação aos Princípios da Filosofia do Direito, tratar a justiça social como uma prerrogativa fundada na exigência de reconhecimento recíproco desdobrado de relações de reconhecimento historicamente amadurecidas e institucionalizadas (Honneth, 2010: 8). Todavia, da autorreflexão de Honneth não se produz somente o tipo de reconhecimento que ele denominou de receptivo por nele estar implicado um reposicionamento da consciência em relação à percepção de seu objeto, mas também um significativo e estratégico distanciamento de Hegel. Isto se dá preponderantemente numa obra bem anterior a que está aqui sendo considerada, notadamente naquela publicada originalmente em $2003 \mathrm{e}$ emblematicamente intitulada Unsichtbarkeit (Invisibilidade) (Honneth, 2003a).

\section{0 reconhecimento para além de Hegel}

O capítulo que aqui nos interessa é o que confere (parcialmente) o título à obra: Unsichtbarkeit. Über die moralische Epistemologie von Anerkennung (Invisibilidade. Sobre a epistemologia moral do reconhecimento). O cerne do distanciamento de Honneth dá-se, no capítulo da obra anterior referida, em íntima relação com um aspecto basilar da Fenomenologia do Espírito de Hegel: em 
Hegel estava pressuposta a ideia de que o reconhecimento deve ser precedido pelo conhecimento. De fato, na Fenomenologia do Espírito, o reconhecimento pleno só é possível na medida em que o espírito, ao se exteriorizar e se relacionar com a natureza, deve retornar para o espírito na forma do conceito. É evidente, pois, que para Hegel, assim como supunha Honneth em sua obra fundante da teoria do reconhecimento, o conhecer é pressuposto do reconhecimento.

No prefácio da aqui comentada obra de 2003, Honneth, em mais um de seus vários louváveis momentos de autocrítica, afirma, em relação ao reconhecimento de matriz hegeliana: "Durante muito tempo parecia-me não se ocultar, em relação a este tema, nenhum mistério, por que eu estava seguro, em relação a Hegel, de ter a solução certa nas mãos" (Honneth, 2003a: 7, tradução nossa). Embora reconheça a plausibilidade do uso de Hegel para a compreensão de muitas formas e relações de reconhecimento contemporâneas, Honneth afirma enfaticamente que o paradigma hegeliano do reconhecimento não pode mais conferir a solução adequada (Idem, Ibidem). Para fundamentar a ideia de pensar o reconhecimento para além do pressuposto hegeliano, Honneth vale-se da referência a uma das esferas de interação, o amor, e reporta-se ao comportamento espontâneo e às disposições de uma pessoa em relação às necessidades de uma criança em situação de carência - aqui fazendo clara referência à psicanálise winnicottiana por ele incorporada:

Não é assim, que a gente precise perfazer um conhecimento que nos leve a perceber em nosso defrontante uma criança carente de ajuda para que manifestemos gestos de estímulos e de solidariedade; mais que isso, reagimos diretamente à percepção da criança com expressões com as quais fundamentalmente trazemos à tona nossa preferência por ela (Honneth, 200za: 17-18, grifos nossos).

Vê-se que Honneth projeta aqui o ideal de uma forma de reconhecimento direto, não mediado, e com isso, parece reavaliar e revalorizar o caráter fecundo da primeira esfera de interação por ele desenvolvida, inspirado por Hegel: o amor. Com efeito, na Realphilosophie de Iena Hegel havia considerado o amor $o$ elemento da eticidade, mas não ainda ela própria. No amor estaria o pressentimento da eticidade (Idem: 79), o que significa considerar que "a experiência de ser amado constitui para cada sujeito um pressuposto necessário da participação na vida pública de uma coletividade" (Idem, Ibidem), justamente por que é esta experiência que permite a formação de um referente intrapsíquico fundamental para a noção de comunidade ética (Idem: 80). 
No texto aqui em pauta, no entanto, em que Honneth se situa para além de Hegel, o reconhecimento é depurado de seus pressupostos cognitivos, na medida em que este se dá sem o suporte do conhecimento prévio e adquire, assim, um caráter performático, pois se sustenta em uma manifestação expressiva (expressiver Ausdruck) de cuidado (Fürsorge) e atenção (Achtung) diante da criança carente de ajuda (2003a: 18). As manifestações expressivas comportam atitudes quase instintivas que se tornam visíveis nos gestos, no sorriso, no abraço, nas expressões faciais e nas mímicas e dão à criança "sinais altamente diferenciados de prontidão para a interação" (Idem: 17) reconhecente. Neste sentido Honneth procura responder à questão, por ele mesmo formulada, se as relações de reconhecimento entre adultos poderiam ser constituídas por meio de tais manifestações expressivas, e conclui que:

Também adultos em suas comunicações rotineiras dão, através de inúmeras expressões sutis, a compreender que estes (seus defrontantes - ASB) são bem-vindos ou merecem atenções especiais (...). Quando realizamos um gesto de reconhecimento em relação à outra pessoa, damos a ela performativamente a entender que nos vemos, em relação a ela, comprometidos com um tipo determinado de comportamento ligado ao seu bem-estar (Idem: 19-21, tradução nossa).

Importa salientar que na forma de reconhecimento aqui pensada a autolimitação desempenha também um papel central, pois o sujeito reconhecente precisa, com seu gesto de cuidado e atenção, realizar um descentramento de sua individualidade, que seja capaz de romper com o amor próprio (Selbstliebe) para engendrar e conferir um valor positivo ao outro, de modo que este valor se constitua em fonte de sua legítima pretensão de ser reconhecido, todavia, também em situações que se situam além do mero gesto expressivo. O sujeito reconhecido, portanto, é equipado com a autoridade moral de cultivar expectativas extensivas diante do sujeito reconhecente:

Quando reconheço alguém e confiro a ele (...) uma autoridade moral sobre mim, estou originalmente motivado a tratá-lo futuramente de acordo com o seu valor (por mim a ele atribuído - ASB) (Idem: 22).

O reconhecimento constitui aqui, pois, uma atitude independente de uma ação prévia emanada do outro e se afirma enquanto ato autônomo em relação a qualquer demanda porventura interposta (Idem: 8), portanto, manifesta-se antes mesmo da erupção do conflito: "o reconhecido é reconhecido como válido imediatamente" (Honneth, 2003: 85). Considere-se, todavia, que esse tipo 
de reconhecimento imediato só é novo aqui em seu aspecto contextual, pois o próprio Hegel já o havia pensado na Realphilosophie de Iena, na qual insere o contrato social nas determinações intersubjetivas capazes de configurar um "consenso normativo mínimo" (Honneth, 2003: 85), de modo a minar as bases atomistas do direito natural de tipo hobbesiano, que considera o contrato um mero preceito da prudência, cuja finalidade é a intensificação preventiva do poder com vistas a garantir a autoconservação individual. Pois, para Hegel, mesmo no Contrato, "os sujeitos precisam ter-se reconhecido mutuamente de alguma maneira antes de todo conflito" (Idem: 85).

Interessante aqui é que Honneth transporta um tipo de reconhecimento pensado por Hegel em relação a um aspecto institucional - o Contrato - para um contexto diferenciado e performático de manifestações expressivas, cuja eficácia não é menor em relação ao primeiro tipo, pois funda o terreno pelo qual a orientação para a ação deve se pautar pela autoridade moral conferida e, portanto, compartilhada com o outro (Honneth, 2003a: 27). Porém, outro avanço do texto em pauta parece residir no fato de Honneth tentar expandir a esfera do amor para além do modelo winnicottiano, que a centra fortemente na relação estabelecida entre a mãe e a criança. A pergunta de Honneth, se as manifestações expressivas podem serem transpostas da criança para os adultos é emblemática a este respeito. Ele parece querer inscrever na esfera de interação do amor momentos de socialização e, portanto, de conflito e de Luta por Reconhecimento, não restritos às relações primárias típicas da infância. É ele próprio que afirma, no texto que estamos aqui reconstruindo, literalmente:

Eu não vejo qualquer razão para não transportar o caso isolado da socialização infantil primária ao mundo social como um todo e, com isso, afirmar uma percepção valorativa também para a integração de adultos (Honneth, 2003a: 16, tradução nossa).

O cerne dessa revisão tange, no fundo, uma questão explicitamente afirmada por Honneth em relação ao amor, e em oposição a ela, em Luta por Reconhecimento, segundo a qual

O amor, como forma mais elementar do reconhecimento, não contém experiências morais que possam levar por si só à formação de conflitos sociais (...). Os objetivos e os desejos ligados a isso (...) não se deixam generalizar para além do círculo traçado pela relação primária, de modo que pudessem tornar-se um quadro moral de conflitos sociais, porque dependem de critérios socialmente generalizados (...) (Honneth, 2003: 256). 
Na obra Luta por Reconhecimento, portanto, a esfera do amor era vista como um tipo específico de relação encerrada nos estreitos limites "de uma relação primária" (Idem: 257) e, com isso, interpretada como estéril para processos de universalização social (Idem, Ibidem). Uma dificuldade adicional e de grande envergadura na obra Luta por Reconhecimento em relação à constituição da esfera do amor vincula-se também, ali, ao não tratamento sistemático das obras de maturidade de Hegel, pelas razões que já expusemos e tentamos aqui reposicionar nos quadros de seu arcabouço teórico-conceitual, com base em sua própria produção posterior.

Ocorre que, estando ausente da reflexão de Honneth por ocasião da publicação de Luta por Reconhecimento em 1992, a esfera do amor foi ali constituída tendo como parâmetro normativo somente os escritos do jovem Hegel, não fluindo para o domínio interior dessa esfera as formas específicas de constituição das comunidades familiares (Familiengemeinschaften), em conformidade com o tratamento atribuído a elas nos Princípios de Filosofia do Direito. Ora, os padrões internos do reconhecimento nos domínios do amor e da família submetem-se a princípios reguladores bastante distintos. É de fato em obra posterior, intitulada Das Andere der Gerechtigkeit. Aufsätze zur praktische Philosophie (O outro da justiça. Ensaios sobre a filosofia prática) e publicada no ano 2000 (Honneth, 2012), no capítulo Zwischen Gerechtigkeit und affektiver Bindung. Die Familie im Brennpunkt moralischer Kontroversen (Entre justiça e vínculo afetivo. A familia no centro de controvérsias morais), que Honneth procura sistematicamente diferenciar os contornos internos dos dois domínios, ao discuti-los e submetê-los a uma análise circunstanciada do potencial moral implícito nas identidades familiares modernas. Rejeitando considerar o amor e a família como grandezas estáticas, Honneth furta-se, no referido capítulo do livro em pauta, à realização de uma discussão substancial sobre o conteúdo desses domínios, e procura dar uma resposta procedimental (prozeduralistische Antwort) às questões que eles suscitam (Idem: 215).

Segundo Honneth, com o processo de industrialização, o novo ideal de família requeria que o casamento se fundasse, diferentemente das exigências típicas de comunidades tradicionais, enquanto prática assentada no sentimento de amor recíproco e, portanto, independente de pressões externas, deslocando-se os problemas morais de fora para dentro de suas estruturas (Idem: 193). No entanto, desde o início de seu processo de destradicionalização (Enttraditionalisierung) e desconvencionalização (Entkonventionalisierung), a família sempre esteve no centro de disputas normativas. O processo de diferenciação e autonomização da família, ao lado da proibição do trabalho infantil e da nova 
regulação jurídica da distribuição de bens e papéis entre seus membros, teria também contribuído para dissolver, ao longo dos Séculos XIX e XX, o nexo normativo entre amor e família (Idem: 198) e transformado as antigas pretensões morais em direitos sancionados pelo Estado - fato que teria empurrado as dinâmicas da esfera pública, novamente, para o interior da esfera privada da família (Idem: 210).

Com a autonomização, diferenciação e destradicionalização, alteram-se as obrigações relativas a direitos e deveres e surgem de modo ambivalente e paradoxal novos riscos e aberturas estruturais que podem desencadear lutas internas por reconhecimento entre os membros das comunidades familiares. Segundo Honneth, sempre que "um membro da família se sentir ameaçado em sua integridade pessoal, os direitos precisam garantir um espaço com o qual este membro, em sua própria defesa, possa se proteger" (Idem: 209, tradução nossa). Evidencia-se, pois, que as demandas por reconhecimento não se articulam somente de dentro das esferas de reconhecimento supostamente harmônicas em relação a uma negação ou lesão externa, mas podem resultar de disputas normativas em seu próprio interior. No caso específico em pauta, os membros das comunidades familiares podem reclamar, em seu próprio benefício, a extensão daqueles direitos universais quando não se sentirem reconhecidos com a dignidade de pessoas portadoras de direito (Idem, Ibidem). Estamos certos de que essa perspectiva pode ser também considerada em relação às outras esferas de reconhecimento, embora Honneth tenha dedicado a ela pouco ou nenhum espaço significativo. Mesmo nos estudos específicos sobre as dinâmicas dos movimentos sociais, as disputas, as alianças e as dissidências internas são muito relevantes para não serem merecedoras de um tratamento mais sistemático (Cf. Gohn, 1997; Soares Do Bem, 2006). Sem dúvida, sob essa perspectiva, parte considerável da história dos movimentos sociais poderia ser reescrita, de modo a permitir a compreensão das identidades coletivas como "um processo objetivo-subjetivo de negociação constante, que redefine as práticas e posturas grupais" tanto em relação às suas estruturas internas como externas (Prado, 2006: 209).

Feitas as devidas atualizações no sentido de incorporar à obra Luta por Reconhecimento elementos da reavaliação posterior de Honneth em relação ao conteúdo das obras de maturidade de Hegel, podemos agora retroceder àquele momento da obra no qual identificamos o salto gigantesco e o deslocamento em direção à psicologia social de George H. Mead. Naquele contexto, a justificativa de Honneth para o deslocamento em relação a Hegel, anterior à reavaliação autocrítica que acabamos de expor, fundava-se na necessidade de extrapolar as 
características metafísicas da reflexão hegeliana (Honneth, 2003: 120), de modo a possibilitar a reconstrução e tradução de sua teoria da intersubjetividade à luz de uma teoria pós-metafísica, amplamente reconhecida por Honneth como assente na obra de Mead, em que pese o fato de ele também, reiteradamente, reconhecer que tanto em Hegel como em Mead o reconhecimento está intimamente vinculado à noção de evolução moral da sociedade (Idem: 125). Dessa justificativa mais geral decorrem outras - as que estão implicadas na necessidade de submeter os pressupostos metafísicos de Hegel a uma fenomenologia empiricamente controlada em relação aos padrões de reconhecimento (amor, direito, eticidade) (Idem: 121) e à imperiosa tarefa de localizar, nesses padrões, também os seus núcleos negativos, de modo a integrar no processo da luta por reconhecimento as experiências de desrespeito (Idem: 122).

O passo crucial de Mead para fundamentar de modo naturalista o reconhecimento hegeliano dá-se com a distinção entre o $I$ e o $M e$, vistos como parceiros intersubjetivos no processo de constituição do self (Honneth, 2003: 130). Enquanto o Me carrega o resultado de uma autorrelação originária e força 0 indivíduo a conscientizar-se de si na posição do objeto, o $I$, que é fonte não regulamentada de suas ações presentes, deve se abrir para as expectativas normativas do $M e$, nas quais se supõem já integrados os comportamentos morais no julgamento das ações (Idem: 133). Ao exemplificar esse mecanismo, Mead distingue duas formas de autorrelação da criança no jogo lúdico: o play e o game. No domínio do play, a criança imita um parceiro concreto da interação imaginária, enquanto no game a criança se defronta com vários parceiros e, com isso, desenvolve a sensibilidade para absorver as normas sociais de um "outro generalizado" (Idem: 134).

Na passagem do comportamento lúdico da criança, da etapa do play para o game e deste para a assunção da perspectiva do outro generalizado, Honneth vê em Mead a aplicação e explicação do processo de socialização (Idem: 135), por meio do qual:

O elo conceitual entre o campo mais estreito e o mais amplo (...) se efetua na forma de uma interiorização de normas de ação, provenientes da generalização das expectativas de comportamento de todos os membros da sociedade (Idem, Ibidem).

A adoção da perspectiva do outro generalizado pela criança é que permite entender tal perspectiva por meio da noção de reconhecimento, pois "pela via da interiorização de suas atitudes normativas, ela própria pode saber-se reconhecida como um membro de seu contexto social de interação" (Idem: 136), ao 
mesmo tempo em que esta aprende a conceber-se como pessoa de direito e a desenvolver uma atitude positiva para consigo - o autorrespeito - ante o reconhecimento conferido pelos demais membros da comunidade (Idem: 137).

Embora não adote uma postura crítica radical em relação ao modelo interpretativo de Mead, como o faz Habermas em publicação de 1981 (Habermas, 2016: 70-71), Honneth aduz que a mera interiorização da perspectiva do outro não é suficiente para construir a identidade moral, pois entre o I e o ambiente social pode surgir um conflito moral que, em situações dadas, concorre para separar o indivíduo da comunidade (Idem: 140). No entanto, vê tais diferenças morais como o substrato para a abertura de uma rede de possibilidades para a proliferação de ideais normativos que podem contribuir para fazer crescer, simultaneamente, tanto a autonomia individual como a ampliação dos horizontes éticos da comunidade (Idem: 143-146).

\section{As mudanças estruturais das comunidades e a constituição das modernas esferas do direito e da estima social}

É curioso observar que o modo de aparição da comunidade em Luta por Reconhecimento se dá apenas de modo indireto nas partes em que são elaboradas as abordagens epistêmicas, pois, nestes contextos discursivos, ela não é considerada, ainda, segundo uma referencialidade interna. Nestas partes da obra, nas quais se buscam a gênese e os desdobramentos teóricos da eticidade, a comunidade aparece como o lugar onde se efetivam e se manifestam os ideais normativos resultantes da reflexão, por ser nela que repousam e se materializam, em última instância, os contornos que conferem efetividade à noção de boa vida. Ela figura, pois, na parte mais sistemática da obra, como um pressuposto, não problematizado, da encarnação dos ideais éticos, por não se constituir, ainda, como uma categoria analítica. Ela só irá aparecer como tal, e ainda assim de modo relativo, no capítulo 5 da parte II, no qual Honneth discute os padrões de reconhecimento intersubjetivo (amor, direito, solidariedade) e efetivamente inscreve tais padrões no fluxo da mudança e das mediações históricas.

É nos contextos da obra em que as obrigações éticas (ethische Verpflichtungen) são tratadas como resultantes de processos decisórios intramundanos decorrentes de transformações históricas que alteram a configuração das esferas de interação do direito e da estima social e onde já se encontra uma reflexão sobre a compreensão cotidiana do caráter específico da ordem social (Honneth, 2003: 203), que a comunidade vai, pouco a pouco, adquirindo visibilidade enquanto categoria analítica. Porém, é num dos capítulos de obra publicada 
originalmente em 2000 e intitulado Posttraditionale Gemeinschaften. Ein konzeptueller Vorschlag (Comunidades pós-tradicionais. Uma proposição conceitual) (Honneth, 2012: 328-338) - da qual extraímos um capítulo para analisar, nos parágrafos anteriores, a família enquanto objeto de controvérsias morais -, que a comunidade é enfaticamente tratada de modo analítico.

Saliente-se que o capítulo aqui focalizado, diferentemente daquele sobre as comunidades familiares (Familiengemeinschaften), não traz grande novidade em relação à comunidade, mas esta é, porém, tratada agora com base em uma normatividade própria. É, pois, justificativa plausível que iniciemos nossa exposição reconstrutiva tendo como base esse capítulo, embora tenhamos também que nos respaldar no capítulo de Luta por Reconhecimento, no qual são discutidos os padrões de reconhecimento, já que Honneth a ele reiteradamente se refira, de modo confirmador. Diante do que identifica como uma grande ausência de clareza conceitual em relação ao que se entende por comunidade sob as condições específicas das modernas sociedades, Honneth procura definir um conceito mínimo de comunidade e salienta que ela pressupõe "formas de relações sociais (...) definidas pela orientação a um bem coletivamente compartilhado, ou seja, a valores intersubjetivamente considerados como válidos" (Honneth, 2012: 330, tradução nossa).

Com a adoção de um conceito mínimo evidencia-se que Honneth evita tratar o conceito de comunidade de modo substancial, pois ela não deve ser de "qualquer natureza" (nicht beliebiger Art sein), "mas possuir um caráter normativo" (Idem: 328) e, portanto, ser compatível com uma determinada medida de consistência intersubjetiva e solidária implícita na realidade normativa de sociedades liberal-democráticas e ter já incorporado em seu arcabouço os princípios culturais e éticos das mesmas (Idem, Ibidem). Por isso considera que a tradição clássica da sociologia não tem, em relação a este tema, grande contribuição a dar para o esclarecimento do conceito de comunidade, pois se distanciando em mais de cem anos das sociedades contemporâneas não apenas varia enormemente de um autor para outro como funde as abordagens destes autores às concepções específicas sedimentadas em suas obras (Idem: 330). Neste sentido, Honneth cita apenas a produção tardia de Durkheim, em quem vê a existência de comunidades sociais como estruturas vinculadas a uma situação de retorno periódico de fusão coletiva (Idem, Ibidem) e também a produção clássica de Tönnies, na qual os sujeitos só podem se saber unidos em comunidades por considerá-las expressões de suas próprias inclinações e necessidades individuais (Idem: 331).

No entanto, de Tönnies Honneth apropria, pelo menos, a diferenciação por ele feita entre comunidade e sociedade. Em relação à primeira, considera que a 
integração social é nela significativa na medida em que os membros se estimam em suas propriedades e capacidades na condição de sujeitos ou grupos de pessoas determinados, mantendo entre si relações de solidariedade; em relação à segunda, considera que nela a integração social é significativa na medida em que as propriedades encontram reconhecimento recíproco ao serem compartilhados por todos os seus membros (Idem, Ibidem).

Podemos agora retornar à obra Luta por Reconhecimento, pois é nela que se pode verificar a ênfase colocada por Honneth nas mudanças históricas que alteram substancialmente as estruturas hierárquicas que reconfiguram as comunidades, assim como a estrutura das esferas de interação ou os padrões de reconhecimento do direito e da estima social.

Em comunidades tradicionais, de natureza estamental, as esferas do direito e da estima social apresentam-se ainda indiferenciadas e submetidas à eticidade convencional, que define tarefas, direitos e deveres por meio de critérios de avaliação centrados em papéis sociais focados na ideia de cooperação intragrupal, sendo reguladas por honra e status, ao preço evidente de uma indisposição - quando não de uma luta ferrenha e dogmática - em relação aos grupos circundantes. Na transição para a modernidade, a estima social desvincula-se da esfera do direito e das expectativas específicas em relação aos papeis sociais típicos das comunidades tradicionais, uma vez que o reconhecimento jurídico pressupõe a extensão do direito, indistintamente, a todos os cidadãos livres.

O desacoplamento histórico entre o reconhecimento jurídico e a estima social produz, por decorrência, o surgimento de duas formas distintas de respeito: o primeiro, ligado ao direito, postula o respeito universal pela liberdade da pessoa e a vincula à sua imputabilidade moral, não tolerando, pelo menos formalmente, nenhuma gradação em relação à sua aplicação, porém esta esfera pode se constituir em "um dos lugares em que pode suceder uma luta por reconhecimento" (Honneth, 2003: 186), justamente por que tem diante de si a tarefa inadiável de definir "a que círculo de sujeitos ele deve se aplicar" (Idem, Ibidem); o segundo, ligado à estima social, submete o reconhecimento às realizações individuais, "cujo valor se mede pelo grau em que (estas - ASB) são conhecidas por uma sociedade como relevantes" (Idem: 184), ancorando-se num "sistema referencial valorativo no interior do qual se pode medir o 'valor' das (suas ASB) propriedades características" (Idem: 187).

Com o desacoplamento histórico e, sob condições modernas, a esfera do direito (e também da estima social) abre-se estruturalmente para ampliações cumulativas, absorvendo sempre novos pressupostos para a inclusão de avanços no processo de formação racional da vontade individual e coletiva, que 
decorrem, por sua vez, da ampliação correlata das pretensões de validade (Geltungsansprüche) - para usar um conceito tão caro a Habermas - com vistas à ampliação das normas jurídicas. A ordem jurídica moderna, pois, sob o impacto das lutas sociais, passa a subordinar-se crescentemente ao postulado "de não admitir mais, em princípio, exceções e privilégios” (Idem: 190, grifos nossos), como aqueles característicos da ainda indiferenciada esfera da estima social em sociedades organizadas de modo estamental.

O desacoplamento e a subsunção da estima social, por sua vez, ao processo das relações pós-tradicionais, passaram a exigir novas formas de mediação social, capazes de expressar as diferenças individuais, mas agora de modo universal e intersubjetivamente vinculante. Por isso, a determinação de seus critérios orientadores é mais complexa, pois tem que, forçosamente, estar fundada em um quadro de orientações simbolicamente constituído, "sempre aberto e poroso" (Idem: 200), ligado à autocompreensão cultural de uma dada sociedade (Idem, Ibidem) e, neste sentido, o seu alcance e a sua medida dependem do "grau de pluralização do horizonte de valores socialmente definido" (Idem, Ibidem):

Quanto mais as concepções dos objetivos éticos se abrem a diversos valores e quanto mais a ordenação hierárquica cede a uma concorrência horizontal, tanto mais a estima social assumirá um traço individualizante e criará relações simétricas (Idem, Ibidem).

Se em comunidades tradicionais a estima era previamente determinada em relação a propriedades atribuídas a grupos inteiros de acordo com o lugar por eles ocupados na hierarquia social, sob relações modernas ela força a entrada dos sujeitos no campo de uma disputa por significação enquanto grandeza biograficamente individuada (Idem: 204), fazendo com que os antigos princípios definidores da honra migrem para o interior das novas formas de regulação e legitimação e adquiram validade universal por meio do conceito de dignidade humana, no qual está subentendido o direito à garantia igualitária de proteção da reputação social (Idem, Ibidem). Com isso, o conceito estamental de honra reflui, do espaço público que antes ocupara, para o interior da esfera privada e, em seu lugar, emerge, gradativamente, sob condições modernas, as categorias de reputação ou prestígio social. Uma vez privatizada a honra, a estima social libera-se tanto dos privilégios jurídicos aos quais estava associada como de sua configuração enquanto qualidade moral da personalidade (Idem: 206), vinculando-se crescentemente ao reconhecimento resultante da contribuição e do desempenho dos indivíduos em relação à implementação prática dos objetivos sociais. 
Como os objetivos sociais só podem ser "abstratamente definidos" (Idem, Ibidem), a organização da moderna estima social adquire o caráter de um "duradouro conflito cultural" (Idem, Ibidem) e passa a sempre exigir uma práxis exegética apta a possibilitar a identificação do valor das propriedades e capacidades, que, por sua vez, remete reiteradamente, às interpretações historicamente constituídas sobre as finalidades sociais. Se é, pois, na própria práxis exegética que se funda o "conflito cultural de longa duração" (Idem: 207), o conteúdo das interpretações sobre propriedades e capacidades da autorrealização depende do modo como cada grupo social "consegue interpretar de maneira pública as próprias realizações e formas de vida como particularmente valiosas" (Idem, Ibidem).

Aqui se evidencia, em relação à esfera da moderna estima social, que a autocompreensão cultural que a condiciona é, ao mesmo tempo, parte constitutiva da luta por reconhecimento, que pressupõe "uma luta permanente na qual os diversos grupos procuram elevar, com os meios da força simbólica e em referência às finalidades gerais, o valor das capacidades associadas à sua forma de vida" (Idem, Ibidem). Sendo o conflito duradouro, as lutas por reconhecimento só podem alcançar uma estabilidade temporária das relações que bloqueiam a elevação da estima social e, ainda assim, se forem capazes de influenciar, com determinação, o clima das atenções públicas, conquistando visibilidade social:

Quanto mais os movimentos sociais conseguem chamar a atenção da esfera pública para a importância negligenciada das propriedades e das capacidades representadas por eles de modo coletivo, tanto mais existe para eles a possibilidade de elevar na sociedade o valor social ou, mais precisamente, a reputação de seus membros (Idem: 208).

\section{Considerações Finais}

Para concluir, cumpre destacar, segundo o que demonstramos ao longo deste artigo, o relevo da comunidade na teoria do reconhecimento de Axel Honneth em suas diferentes formas de manifestação nos planos epistêmico, fenomênico e histórico. Demonstramos que mesmo nos contextos discursivos em que aparece como grandeza (aparentemente) secundária, como no âmbito da reflexão epistêmica com vistas à constituição da noção de reconhecimento intersubjetivo, a comunidade é central por demarcar fronteiras dinâmicas entre o público e o privado (Leal, 2006: 184) e por constituir-se no locus privilegiado por onde transitam diferentes realidades culturais que articulam de modo tenso e complexo, as identidades individuais e coletivas (Idem, Ibidem). 
Demonstramos também que com o deslocamento do plano epistêmico para os planos fenomênicos e históricos, a comunidade emerge como categoria analítica e suas lógicas de reconhecimento, de pertença e de diferenciação podem ser finalmente abordadas segundo uma referencialidade interna e permite vislumbrar as mudanças das estruturas hierárquicas das comunidades como resultantes de processos - mais do que de formas cristalizadas - referidos à ação humana e à historicidade (Prado, 2006: 200). É neste contexto que se tornou possível reconstruir, no movimento das transformações históricas das comunidades tradicionais, a gênese das modernas esferas de interação do direito e da estima social.

Apesar de algumas limitações decorrentes das escolhas de Honneth no sentido de desenvolver tão somente uma concepção procedimental - e não substancial - de comunidades, sua abordagem descortina, no entanto, inúmeras e profícuas possibilidades para todos aqueles que têm nelas os seus focos de investigação. Mas como elas são objetos privilegiados em várias outras áreas (e autores) das ciências humanas (Leal, 2006: 183), é certo também que aqueles que querem operar com um conceito mais amplo de comunidade para explicar as múltiplas formas de sobrevivência ou de reinvenção das comunidades tradicionais no interior das modernas estruturas sociais, deverão recorrer, ainda que subsidiariamente, a outras fontes - notadamente àquelas que mais se adequem às suas necessidades e/ou propósitos.

\section{Referências}

DÜSING, Edith. Intersubjektivität und Selbstbewusstsein. Köln, Verlag für Philosophie Jürgen Dinter, 1986.

GOHN, Maria da Glória. Teorias dos movimentos sociais. Paradigmas clássicos e contemporâneos. São Paulo, Loyola, 1997.

HABERMAS, Jürgen. Theorie des kommunikativen Handelns. Zur Kritik der funktionalistischen Vernunft. Band 2. Frankfurt am Main, Suhrkamp, 2016.

HEGEL, Wilhelm Friedrich. Grundlinien der Philosophie des Rechts oder Naturrecht und Staatswissenschaft im Grundrisse. $2^{\text {a }}$. Aufl. Frankfurt am Main, Suhrkamp, 1989. . Phänomenologie des Geistes. Werke 3. Frankfurt am Main, Suhrkamp, 1986.

HONNETH, Axel. Luta por reconhecimento. A gramática moral dos conflitos sociais. São Paulo, Ed. 34, 2003.

. Unsichtbarkeit. Stationen einer Theorie der Intersubjektivität. Frankfurt am Main, Suhrkamp, 2003a.

. Das Ich im Wir. Studien zur Anerkennungstheorie. Frankfurt am Main, Suhrkamp, 2010. 
. Das Andere der Gerechtigkeit. Aufsätze zur praktische Philosophie. Frankfurt am Main, Suhrkamp, 2012.

KONDER, Leandro. Hegel. A razão quase enlouquecida. Rio de Janeiro, Campus, 1991.

LEAL, Bruno Souza. A comunidade como projeto identitário. In: MAIA, Rousiley Celi Moreira; CASTRO, Maria Ceres Pimenta Spínola. Mídia, esfera pública e identidades coletivas. Belo Horizonte, Editora UFMG, 2006, pp. 183-192.

PRADO, Marco Aurélio Máximo. Movimentos sociais e massa: identidades coletivas no espaço público contemporâneo. In: MAIA, Rousiley Celi Moreira; CASTRO, Maria Ceres Pimenta Spínola. Mídia, esfera pública e identidades coletivas. Belo Horizonte, Editora UFMG, 2006, pp. 193-212.

SOARES DO BEM, Arim. A centralidade dos movimentos sociais na articulação entre o Estado e a sociedade brasileira nos séculos XIX e XX. In: Revista Educação e Sociedade, v. 27, n. 97. Campinas, Centro de Estudos Educação e Sociedade - Cedes, 2006, pp. 1137-1157.

Recebido em: 29/10/2018

Aprovado em: 20/03/2020

\section{Como citar este artigo:}

SOARES DO BEM, Arim. O lugar da comunidade na teoria do reconhecimento de Axel Honneth. Contemporânea - Revista de Sociologia da UFSCar, v. 10, n. 1, jan.- abril 2020, pp. 249-272. 